\title{
Influence of Asymmetric Hot Rolling on Microstructure and Mechanical Property of Ti-6Al-4V Alloy Sheet
}

\author{
Li Jianping, ～Liu Zhenguang, Li Jing \\ The State Key Laboratory of Rolling and Automation, Northeastern University, Shenyang 110819, China
}

\begin{abstract}
The experiments of asymmetric/symmetric hot rolling were carried out to investigate the effect of asymmetric hot rolling on the microstructure and the mechanical properties of titanium alloy. The metallographic microstructure, the mechanical property, the fracture morphology and the microscopic orientation of rolled samples were characterized. The results demonstrate that complex strain path is prior to monotonic strain path for refining grains and simultaneously improving the values of strength and ductility, and the grain sizes in asymmetrically rolled specimen surface are smaller than those in specimen center. Asymmetric hot rolling can refine grains more strongly compared with symmetric hot rolling. The values of strength and ductility of asymmetrically rolled specimens are higher than those of symmetrically rolled specimens, and the values of strength and ductility increase with the development of roll speed ratio. The plastic deformation mechanism of asymmetrically rolled specimen may be slip. While, the one of symmetrically rolled specimen may be twin or slip.
\end{abstract}

Key words: asymmetric rolling; titanium alloy; microstructure; mechanical property

Ti-6Al-4V alloy has been widely used in many fields such as aeronautic astronautic and biomedical industries due to its promising thermal stability, high specific strength, excellent corrosion resistance and outstanding biocompatibility ${ }^{[1-3]}$. It is difficult to improve the physical and mechanical properties of titanium alloy with hexagonal close-packed (hcp) structure (alpha titanium) and body-centered cubic (bcc) structure (beta titanium) through the compression plastic deformation owing to the intrinsic characteristic of few slip systems being activated. The shear strain is beneficial to improve plastic deformation as it will easily activate the potential slip systems. The microstructure refinement is a valid way for the enhancement of mechanical properties ${ }^{[4,5]}$. Severe plastic deformation (SPD) plays an important role in the fabrication of metal materials with bulk fine grains, which has been confirmed by many researches ${ }^{[6-8]}$. Several SPD techniques, such as equal channel angle pressing $(\mathrm{ECAP})^{[9]}$, high pressure torsion (HPT) ${ }^{[10]}$, and accumulative rolling bonding (ARB) ${ }^{[11]}$, have been carried out to produce fine grains. At present, the most commonly used SPD techniques for fabricating fine grains is ECAP. This method is proved to be a feasible solution due to the shear strain exerted in the pressing process $^{[12,13]}$. However, the method could only fabricate small bulk in laboratory preciously, and it is not convenient to process the materials in form of plates and sheets. In modern industry, rolling is widely used for the production of structural materials, especially the plates and sheets, on a large scale with high efficiency and low cost. Asymmetric rolling (ASR) is a special rolling method, in which the peripheral velocity of the two working rollers is different from each other. So, extra shear strain, the core of ECAP process, is exerted on specimen. Owing to activation potential slip system, shear strain is beneficial for plastic deformation of metals with hcp structure and bcc structure. Furthermore, shear strain may change the plastic deformation mechanism from the slip and twin to slip. Many experiments demonstrated that shear strain could fragmentize grains and obtain fine grains ${ }^{[14,15]}$. On the other hand, asymmetric rolling could increase the rolling reduction and decrease rolling force compared with symmetric rolling (SR). So, asymmetric rolling combines the merits of large

Received date: May 18, 2015

Foundation item: National Natural Science Foundation of China (51274063)

Corresponding author: Liu Zhenguang, Candidate for Ph. D., The State Key Laboratory of Rolling and Automation, Northeastern University, Shenyang 110819, P. R. China, Tel: 0086-24-836890360, E-mail: liuzhenguangabcd@163.com 
plastic deformation and shear strain. Furthermore, asymmetric rolling is also a SPD technique, which could also be used in industry.

Many experiments confirmed that fine grain could be obtained in pure titanium by asymmetric rolling. Kim et al. investigated the influence of asymmetric cold or warm rolling on microstructure and mechanical properties ${ }^{[16,17]}$. They pointed out that the cold rolled titanium sheet exhibited ultrafine grains with sizes of $0.1 \sim 0.3 \mu \mathrm{m}$ and ultimate tensile strength of 895 915 $\mathrm{MPa}$ due to the formation of shear bands ${ }^{[16]}$. A defect-free pure titanium sheets with shear bands and ultrafine grains could be fabricated through asymmetric rolling at roll speed ratio of $5^{[17]}$. Huang et al. pointed out that the asymmetric rolled pure titanium sheets at $573 \mathrm{~K}$ showed a large Lankford value and a smaller planar anisotropy, resulting in a remarkable improvement in stretch formation with a small decrease in tensile elongation compared with symmetric rolled sheet ${ }^{[18]}$. Furthermore, nano-grained titanium sheet with grain size of $80 \mathrm{~nm}$ has been produced by the combination of symmetric and asymmetric rolling at room temperature, and the annealed titanium possesses ultrafine grains with size 200 $\mathrm{nm}$ even though annealed at $400{ }^{\circ} \mathrm{C}$ for $30 \mathrm{~min}^{[12]}$.

It is clear that the former experiments focused on the pure titanium, and the rolling process of asymmetric cold or warm rolling. There is less research about the effect of asymmetric hot rolling on the microstructure and the mechanical properties of titanium alloy sheet. In the present paper, symmetric and asymmetric hot rolling experiments were carried out to investigate the role of shear strain path (monotonic and complex strain paths) and the roll speed ratio on the microstructure and the mechanical properties of Ti-6Al-4V alloy sheet.

\section{Experiment}

The commercial two-phase titanium alloy Ti-6Al-4V plate with thickness of $48 \mathrm{~mm}$ was used as the starting material, and the final sheet thickness was $4 \mathrm{~mm}$. Asymmetric hot rolling mill equipped with different roller diameters, upper roller diameter $400 \mathrm{~mm}$ and lower roller diameter $480 \mathrm{~mm}$, was used to investigate the role of shear strain path. It is realized by changing specimen rolling direction between adjacent pass, which is illustrated in Fig.1. The side, through which the specimen entered the gap between upper roller and lower roller in the whole rolling pass, was same in the process of monotonic strain path, namely Side A to Side A. The shear strain direction in the process of monotonic strain path was same. However, the side in the process of complex strain path was different in the neighbor rolling pass, namely Side A to Side B. The shear strain direction in the process of complex strain path was opposite. The transformation temperature of $\alpha$ $+\beta \leftrightarrow \beta$ for the tested alloy was estimated to be $\sim 990{ }^{\circ} \mathrm{C}$ through differential scanning calorimetric, which is a common technique to determine transformation temperature. The tested alloy specimens were heated at $980{ }^{\circ} \mathrm{C}$ for $1 \mathrm{~h}$, and originally rolled at $910{ }^{\circ} \mathrm{C}(\alpha+\beta$ region $)$. The finishing temperature was $840{ }^{\circ} \mathrm{C}$. After rolling, the specimens were cooled in air. Asymmetric hot rolling mill with different rolling velocities was used to investigate the influence of roll speed ratio through changing the rolling velocity of upper and lower rollers. The tested specimens were heated at $980{ }^{\circ} \mathrm{C}$ for $1 \mathrm{~h}$. The starting and finishing temperature were 890 and $750{ }^{\circ} \mathrm{C}$, respectively. The specimens were cooled by quenching. Based on the experiment results of shear strain path, complex strain path was chosen in the experiment of roll speed ratio. The rolled specimens in both experiments were annealed at $780{ }^{\circ} \mathrm{C}$ for $1 \mathrm{~h}$. The commercial pure titanium (grade 2) specimen was used to show the effect of shear strain on microscopic orientation. Both asymmetric and symmetric hot rolling was carried out.

The specimens for optical microscopy were etched in solution comprised of $3 \mathrm{~mL}$ hydrofluoric acid, $5 \mathrm{~mL}$ nitric acid and $92 \mathrm{~mL}$ distilled water. The observed sections were perpendicular to the transverse direction (normal direction-rolling direction plane). Three positions, top (the side of slower roller), center and bottom (the side of faster roller), were selected to show microstructure difference. The optical microscope was Leica Dmirm. The tensile specimen had a dog-bone shape with gauge section of $15 \mathrm{~mm} \times 65 \mathrm{~mm}$ $\times 4 \mathrm{~mm}$. The mechanical properties included the yield stress (YS), ultimate tensile strength (UTS) and elongation to failure (EL). Quanta 600 scanning electron microscope (SEM) was used to show the fracture morphology after the uniaxial tensile test. Electron backscattered diffraction (EBSD) was used to show microscopic orientation difference of symmetric and asymmetric rolled pure titanium specimens. EBSD was conducted in Zeiss Ultra 55 field-emission-gun scanning electron microscope (FE-SEM). Electrolytic polishing at room temperature was used to satisfy the specimen surface quality of EBSD examinations at room temperature. The electrolyte solution was $50 \mathrm{~mL}$ perchloric, $950 \mathrm{~mL}$ glacial acetic acid. The operated voltage was $45 \mathrm{~V}$, and current was $0.4 \mathrm{~A}$.

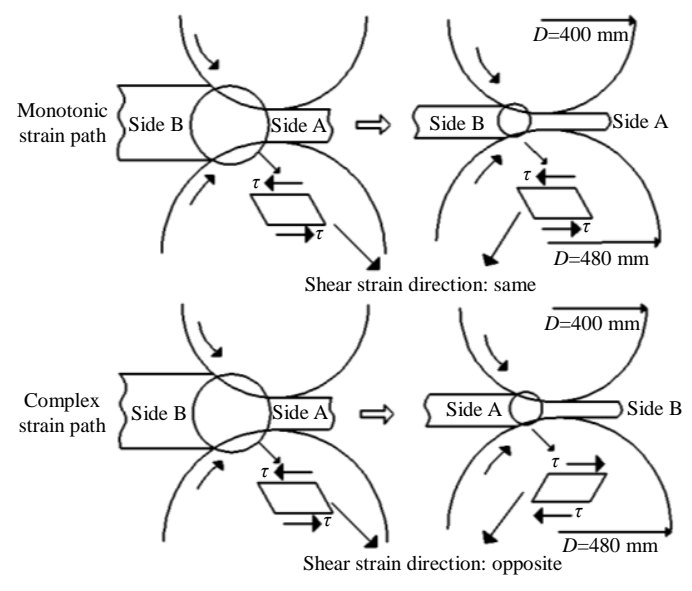

Fig.1 Schematic illustration of shear strain path 


\section{Results and Discussion}

\subsection{Metallographic microstructure of Ti-6Al-4V alloy specimens asymmetrically rolled with different shear strain paths}

Fig.2 shows the microstructure characteristics of asymmetrically rolled specimens after annealing. The grain is ellipse-shape and parallel to rolling direction, indicating that the recrystallization is not completed. In general, the grain sizes in the specimen rolled with a complex strain path are smaller than those with a monotonic strain path. The grain sizes of complex strain path are smaller than those of the monotonic strain path in the same position (a versus $d, b$ versus e, c versus $\mathrm{f}$ ). The grains in Fig.2a are obviously smaller than those in Fig.2d. The distinction of grain sizes between Fig.2b and Fig.2e decreases; however, the grain sizes in Fig.2b are still smaller than those in Fig.2e. The average grain size in Fig.2c is also smaller than that in Fig.2f. Fig.2 demonstrates that the complex strain path is prior to the monotonic strain path in refining grains. In asymmetric rolling process, shear strain is added to asymmetrically rolled specimens, which is similar to the principle of ECAP process $^{[19,20]}$. Fig.1 reveals that the direction of shear strain during the complex strain path is opposite. The mutual circulation of shear strain is more beneficial to fragmentize grains than the single accumulation of shear strain during monotonic strain path process. Therefore, the original grain is divided into many smaller grains after the mutual circulation of shear strain. Fig.2 also reveals that the grains in the specimen surface are smaller than those in the center. Ji et al pointed out that the effective strain along the thickness was inhomogeneous, and the one nearby the surface is larger than that in the center ${ }^{[21,22]}$. The larger shear in the surface will thoroughly fragmentize grains. However, the role on fragmentizing grains in the center is weaker compared with that in the surface. Also, larger effective strain results in more distortion energy, which promotes recrystallization process after hot rolling. So, finer grains are obtained in the surface. In addition, the shear strain in the top surface is also larger than that in the bottom surface. Therefore, the grain sizes of top surface are finer than those of bottom surface.

\subsection{Mechanical properties and fracture morphology of Ti-6Al-4V alloy specimens asymmetrically rolled with different shear strain paths}

According to Hall-Petch relation, fine microstructure promotes mechanical property. Fig.3 lists the mechanical properties of the specimens asymmetrically rolled with different shear strain paths. It is obvious that the values of mechanical properties of the specimens asymmetrically rolled with the complex strain path, YS, UTS and EL, are higher than those with the monotonic strain path. Therefore, rolling with the complex strain path could simultaneously improve strength and ductility compared to that with the monotonic strain path. As Fig.2 shows, the grains in the specimen asymmetrically rolled with the complex strain path are smaller than those with the monotonic strain path. Therefore, the refinement strengthening is the main strengthening mechanism. In the process of plastic deformation, dislocation is formed, and it will accumulate on the grain boundary continuously, leading to the increase of stress level. The dislocation density in the grain boundary of smaller grains is lower than that of
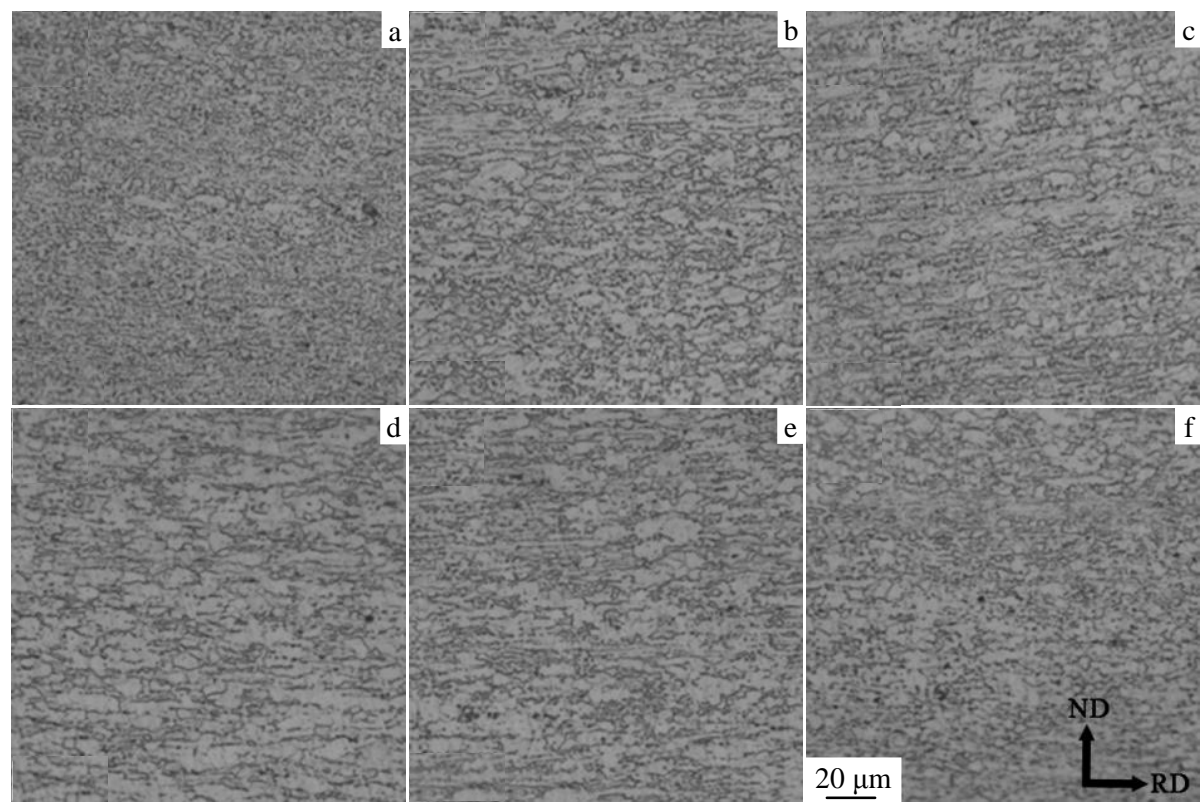

Fig.2 Optical photographs of specimens asymmetrically rolled with different strain paths: $(\mathrm{a} \sim \mathrm{c})$ complex strain path, (d f) monotonic strain path; (a, d) top, (b, e) center and (c, f) bottom 


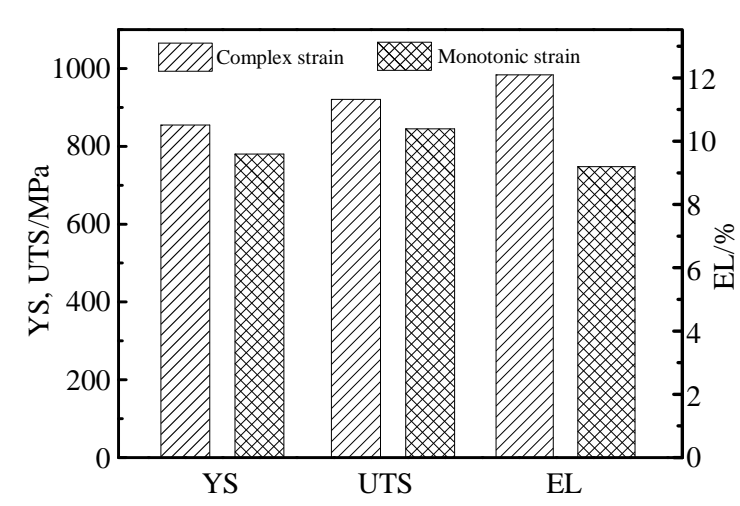

Fig.3 Mechanical properties of Ti-6Al-4V alloy specimens asymmetrically rolled with different shear strain paths

larger grains. When the dislocation density surpasses the limited degree, fracture occurs. Therefore, the fracture delays in the smaller grains. As a consequence, the specimen produced by the complex strain path with finer grains show high strength and excellent elongation to fail.

Fig.4 shows the fracture morphology characteristics of asymmetrically rolled specimens after uniaxial tensile test. Dimples are observed on surfaces of the specimens asymmetrically rolled with both complex and monotonic strain paths, which is the typical ductile fracture behavior. The dimples in Fig.4a are homogeneous, and the fracture surface shows plain morphology. That characteristic indicates that the fracture takes place in every grain simultaneously. However, the dimples in Fig.4b are inhomogeneous and the cliff is observed

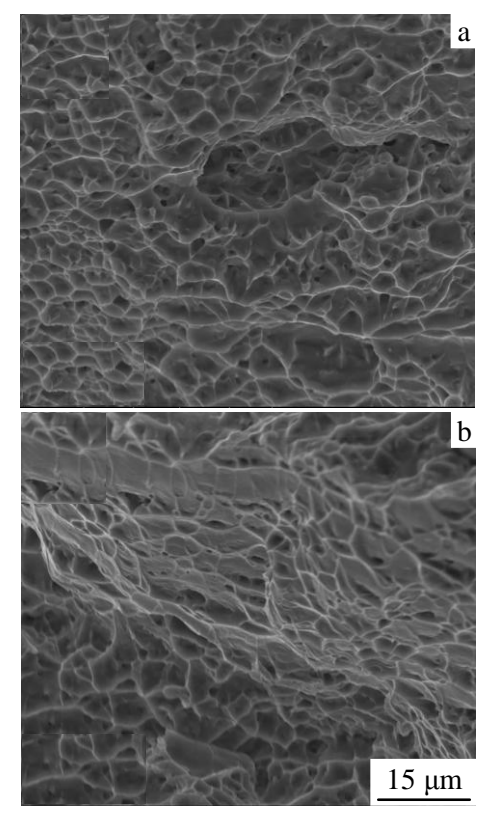

Fig.4 SEM fracture morphologies of specimens asymmetric rolled with different strain paths: (a) complex strain path and (b) monotonic strain path on the fracture surface. That characteristic demonstrates that the fracture occurs suddenly. The dimples in Fig.4a are deeper than those in Fig.4b, which demonstrates that the ductility of the specimen asymmetrically rolled with the complex strain path is better than that with the monotonic strain path. It is also consistent with the elongation to fail (Fig.3). Fig.2 shows that the grains in the specimen produced by the complex strain path are homogeneous, leading to the uniform deformation process. So, the dimple sizes are approximately the same. The grains in the specimen produced by the monotonic strain path are inhomogeneous, resulting in the different deformation process. Therefore, the cliff is observed in Fig.4b.

\subsection{Metallographic microstructure of Ti-6Al-4V alloy specimens rolled with different roll speed ratios}

Fig.5 shows the microstructure characteristics of rolled specimen with different roll speed ratios. It is revealed that grains become finer with increasing roll speed ratio. The grains in symmetrically rolled specimen (Fig.5a) are band shape and paralle to rolling direction. However, the one in asymmetric rolled specimens (Fig.5b and 5c) is equiaxed, which is typical morphology of recrystallization grain. The deformation process under asymmetric rolling can be simplified by two-dimensional strain state of compressive strain along normal direction $\left(\varepsilon_{x x}=-\varepsilon_{z z}\right)$ and simple shear strain along the rolling direction $\left(\varepsilon_{x z}\right)$. The deformation process of symmetric rolling can be expressed by compressive strain along normal direction. So, the equivalent von Mises strain $\left(\varepsilon_{\mathrm{VM}}\right)$ and the displacement gradient tensor $\left[e_{i j}\right]$ in the processes of symmetric and asymmetric rolling are expressed by the following Eqs. (1) (4) ${ }^{[14,23]}$.

$$
\begin{aligned}
& \varepsilon_{\mathrm{VM}-\mathrm{ASR}}=\frac{\sqrt{2}}{3}\left[6 \varepsilon_{x x}^{2}+6 \varepsilon_{x z}^{2}\right]^{1 / 2} \\
& \varepsilon_{\mathrm{VM}-\mathrm{SR}}=\frac{\sqrt{2}}{3}\left[6 \varepsilon_{x x}^{2}\right]^{1 / 2} \\
& {\left[e_{i j}\right]_{\mathrm{ASR}}=\left[\begin{array}{ccc}
e_{x x} & 0 & e_{x z} \\
0 & 0 & 0 \\
0 & 0 & e_{z z}
\end{array}\right]} \\
& {\left[e_{i j}\right]_{\mathrm{SR}}=\left[\begin{array}{ccc}
e_{x x} & 0 & 0 \\
0 & 0 & 0 \\
0 & 0 & e_{z z}
\end{array}\right]}
\end{aligned}
$$

where the indices $x$ and $z$ represent the rolling and normal direction, respectively. Therefore, the asymmetric rolled specimen bears shear strain compared with symmetric rolled specimen, which promotes the plastic deformation and dislocation accumulation. The shear strain is beneficial to fragmentize grains. In addition, the equivalent strain of asymmetric rolling is higher than that of symmetric rolling. So, the larger distortion energy in the asymmetric rolled specimen caused by more dislocation and higher equivalent strain accelerates the recrystallization process, resulting in the fine grains in Fig. $5 \mathrm{~b}$ and $5 \mathrm{c}$. 


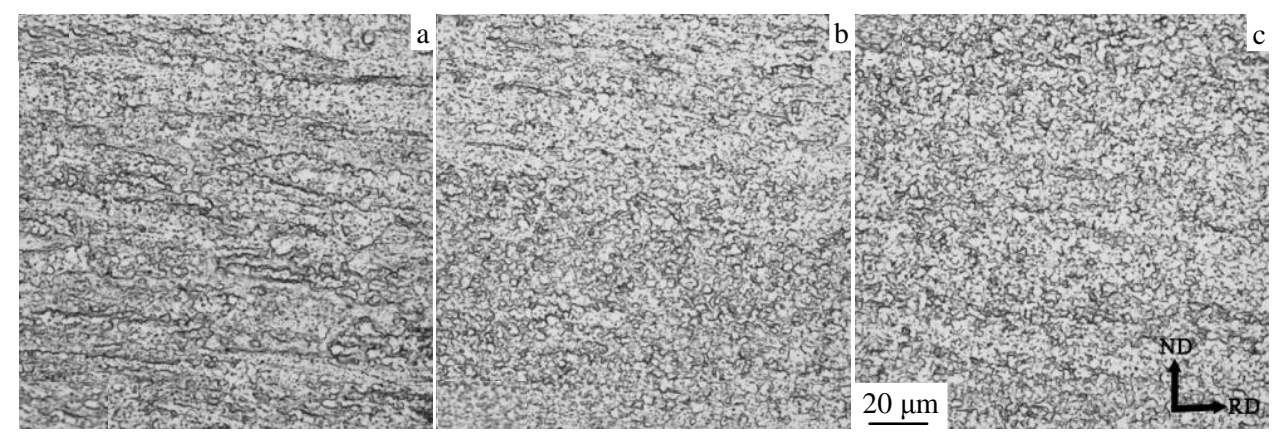

Fig.5 Optical photographs of specimens rolled with different roll speed ratios by the complex strain path: (a) 1.0, (b) 1.1, and (c) 1.2

\subsection{Mechanical properties and fracture morphology of Ti-6Al-4V alloy specimens rolled with different roll speed ratios}

Fig.6 reveals that asymmetric rolling leads to a sharp increase in strength of the rolled specimen together with enhanced ductility compared with symmetric rolling. The values of YS, UTS and EL of the specimens asymmetrically rolled with roll speed ratio 1.1 increase rapidly, in contrast to those of the specimens symmetrically rolled with roll speed ratio 1.0. So, asymmetric rolling is definitely an effective technique to develop simultaneously strength and ductility. However, the yield ratio also amplifies with increasing roll speed ratio, which is harmful to practical application. The values of YS, UTS and EL of specimens asymmetrically rolled with roll speed ratio of 1.2 change little compared with those with roll speed ratio of 1.1. Therefore, roll speed ratio of 1.1 is a good choice. The finer grains (Fig.5b and 5c) contribute to the improvement of strength and ductility.

Fig.7 is the SEM fractographs of specimens rolled with different roll ratios. For the symmetrically rolled specimen (Fig.7a), the fracture morphology presents a poor ductility with large and plain dimples. The fiber characteristic in Fig.7a indicates that the crack propagation is favoring, causing lower strength properties (Fig.6). However, the fracture morphologies of asymmetrically rolled specimens (Fig.7b and 7c) demonstrate a good ductility with small and deep dimples.

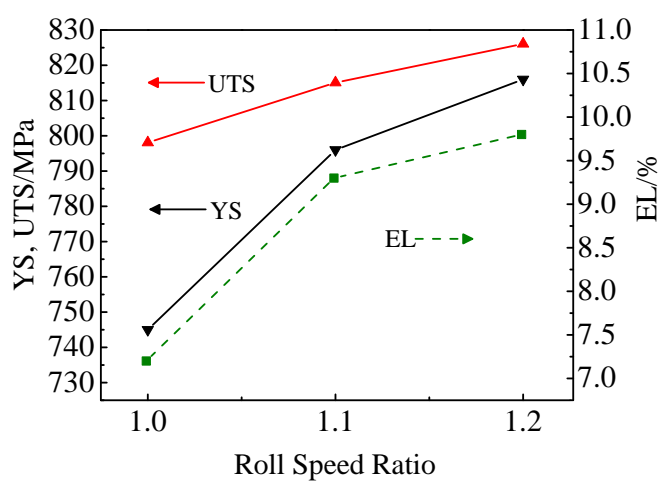

Fig.6 Mechanical properties of specimens rolled with different roll speed ratios by the complex strain path

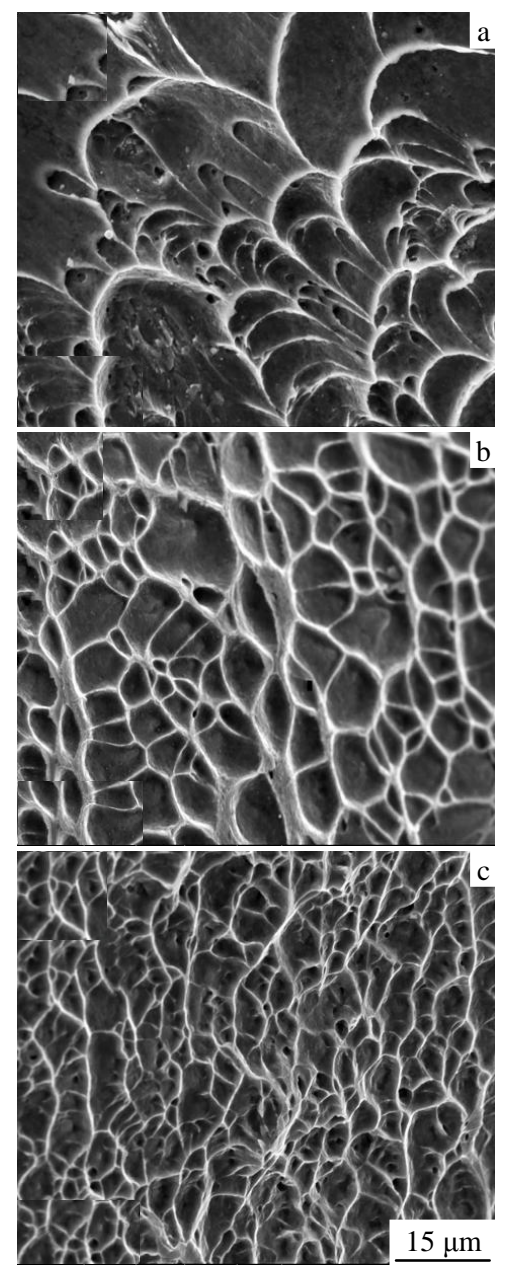

Fig.7 SEM fracture morphologies of specimens rolled with different roll speed ratios by the complex strain path: (a) 1.0, (b) 1.1, and (c) 1.2

The pure dimples demonstrate the high activity of deformation systems at crack tip and high amount of energy release rate, which enhances the strength. The dimple size in Fig. $7 \mathrm{c}$ is smaller than that in Fig.7b. Therefore, the ductility of the specimen asymmetrically rolled with roll speed ratio of 1.2 is better than that with roll speed ratio of 1.1 , which is in agreement 


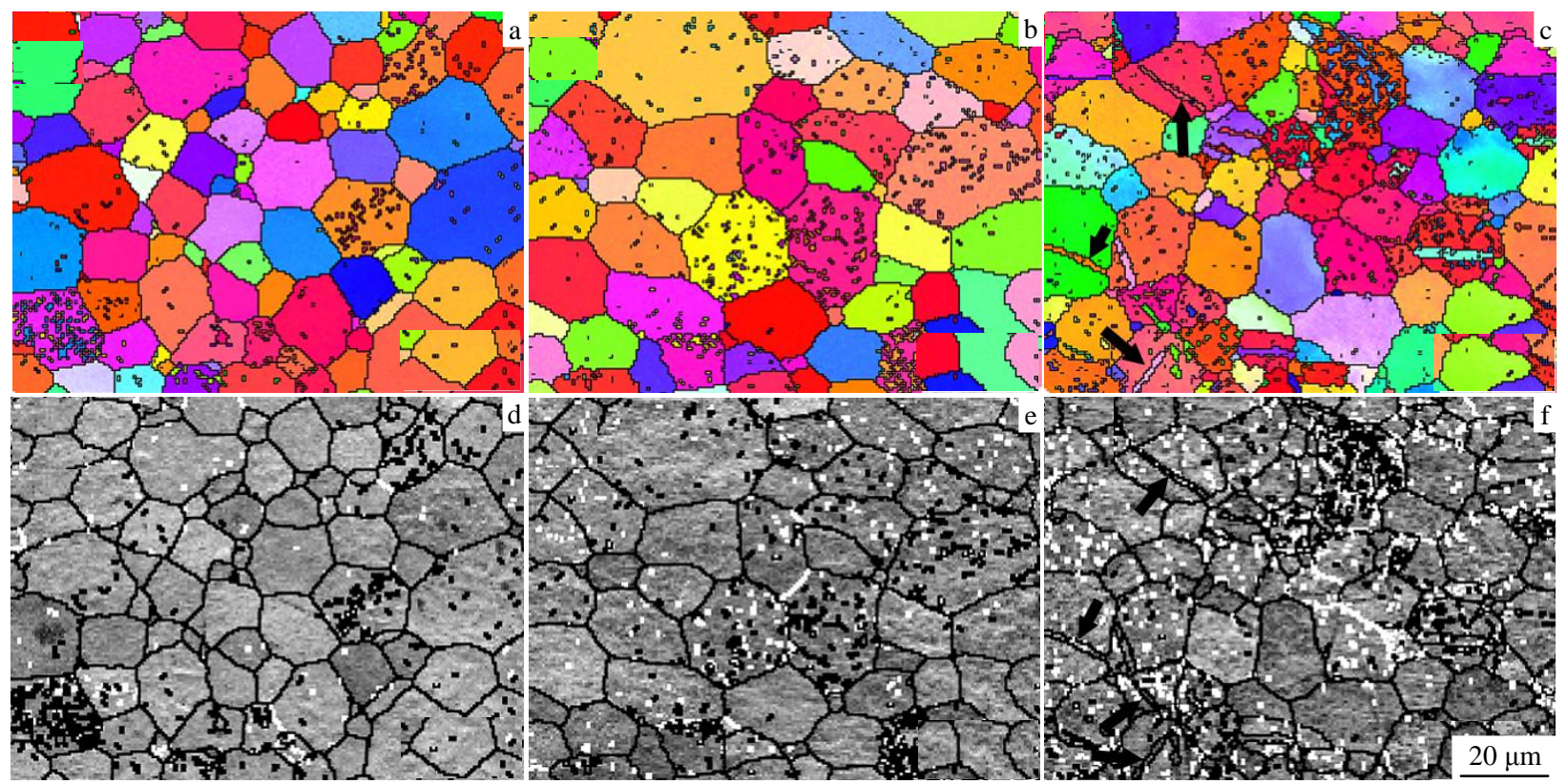

Fig.8 Inverse pole figure maps (a, b, c) and quality images (d, e, f) of pure Ti specimens: (a, d) asymmetric rolled specimens cooled by water; (b, e) asymmetric rolled specimens cooled by air; (c, f) symmetric rolled specimen cooled by air (HAGBs $\left(>15^{\circ}\right)$ as black lines and LAGBs $\left(2^{\circ} \sim 15^{\circ}\right)$ as white ones; Black arrows showing the twins)

with Fig.6. Based on Fig.5, it is revealed that the sizes of dimples on fracture surface are relative to the sizes of grains as the dimple size is dependent upon the initiation site and the grain boundary ${ }^{[12]}$. Large and small dimples respond to fine grains.

\subsection{Microscopic orientation of commercially pure tita- nium specimens rolled by asymmetric and symmetric rolling}

In order to investigate the effect of shear strain exerted by asymmetric rolling on plastic deformation mechanism, commercially pure titanium (grade 2) was used. To preserve the microstructure, the specimens were rapidly water quenched (Figs.8a and 8d). Fig.8 reveals that twins are observed on the symmetrically rolled specimen (Fig.8c and 8f, marked with black arrow), which are not shown on asymmetric rolled specimens. It is accepted that the deformation of pure titanium begins with slip. As the number of active slip systems is less than for bcc and fcc crystal, deformation twin begins to play a crucial role. The general deformation can only be achieved by five independent slip and twinning systems ${ }^{[24]}$. Shear strain could activate the potential slip system, promoting plastic deformation. So, no twins are shown in asymmetrically rolled specimens. On the other hand, twinning system has to be activated owing to the lack of shear strain in symmetrically rolled specimens. Therefore, for hcp structure, the shear strain produced by asymmetric rolling promotes the action of potential slip system. The plastic deformation mechanism also changes from the slip or the twin in the process without shear strain to the slip in the process with shear strain. Misorientation angle distribution demonstrates that high angle grain boundaries (HAGB defined as larger than $15^{\circ}$ ) accumulate on asymmetrically rolled specimens (Fig.8d and 8e). Low angle grain boundaries (LAGB ranging from $2^{\circ}$ to $15^{\circ}$ ) dominate on symmetrically rolled specimen (Fig.8f). So, asymmetric rolling accelerates the formation of HAGB. Asymmetric rolling promotes the crystal rotation owing to shear strain and is beneficial to form HAGB. On the contrary, symmetric rolling lack of shear strain tends to form LAGB through the dislocation accumulation on grain boundary.

\section{Conclusions}

1) The complex strain path is a better way than the monotonic strain path for refining grains and developing the values of both strength and ductility. The grain sizes on specimen surface are smaller than those on specimen center.

2) The grain sizes of asymmetrically rolled specimen are smaller than those of symmetric rolled specimens. The values of strength and ductility of asymmetrically rolled specimens are higher than those of symmetrically rolled specimens. Increase of roll speed ratio could develop mechanical property and ductility.

3) The plastic deformation mechanism of asymmetrically rolled specimen may be slip. While, the one of symmetrically rolled specimen may be twin or slip.

\section{References}

1 Luo Yumeng, Liu Jinxu, Li Shukui et al. Rare Metal Materials 
and Engineering[J], 2014, 43 (11): 2692 (in Chinese)

2 Ye Xiaolin, Tse Zion $\mathrm{T} \mathrm{H}$, Tang Guoyi et al. Materials Characterization[J], 2014, 98: 147

3 Nasiri-Abarbekoh H, Ekrami A, Ziaei-Moayyed A A et al. Materials and Design[J], 2012, 34: 268

4 Zherebtsov S, Kudryavtsev E, Kostjuchenko S et al. Materials Science and Engineering A[J], 2012, 536: 190

5 Valiev R Z, Islamgaliev R K, Alexandrov I V et al. Progress in Materials Science [J], 2000, 45: 103

6 Wang Chengpeng, Li Fuguo, Chen Bo et al. Rare Metal Materials and Engineering[J], 2012, 41(6): 941 (in Chinese)

7 Valiev Ruslan Z. Nanostructured Materials[J], 1999, 12: 35

8 Estrin Y, Vinogradov A. Acta Materialia[J], 2013, 61: 782

9 Yang Xirong, Zhao Xicheng, Fu Wenjie. Rare Metal Materials and Engineering[J], 2009, 38(6): 955 (in Chinese)

10 Shirooyeh Mahmood, Xu Jie, Langdon Terence G. Materials Science and Engineering A[J], 2014, 614: 223

11 Justin L Milner, Abu-Farha Fadi, Bunget Cristina et al. Materials Science and Engineering A[J], 2013, 561: 109

12 Li Zhiming, Fu Liming, Fu Bin et al. Materials Science and Engineering $A[\mathrm{~J}], 2012$, 558: 309

13 Stolyarov Vladimir V, Zhu Y Theodore, Alexandrov Igor V et al.
Materials Science and Engineering A[J], 2001, 299: 59

14 Ding Yi, Jiang Jianhuang, Shan Aidang et al. Materials Science and Engineering $A[\mathrm{~J}], 2009,509: 76$

15 Wauthier Aurelie, Regle Helene, Formigoni Jorge et al. Materials Characterization[J], 2009, 60: 90

16 Kim W J, Yoo S J, Lee J B. Scripta Materialia[J], 2010, 62: 451

17 Kim W J, Yoo S J, Jeong H J et al. Scripta Materialia[J], 2011, 64: 49

18 Huang X S, Suzuki K, Chino Y. Scripta Materialia[J], 2010, 63: 473

19 Valiev Ruslan Z, Langdon Terence G. Progress in Materials Science[J], 2006, 51: 881

20 Furukawa M, Horita Z, Nemoto M et al. Journal of Materials Science [J], 2001, 36: 2835

21 Ji Y H, Park J J. Materials Science and Engineering A[J], 2008, 485: 299

22 Ji Y H, Park J J. Materials Science and Engineering A[J], 2009, 499: 14

23 Sidor Jurij, Miroux Alexis, Petrov Retrov et al. Acta Materialia[J], 2008, 56: 2495

24 Zeng Zhipeng, Zhang Yanshu, Jonsson Stefan. Materials and Design[J], 2009, 30: 3105

\title{
异步热轧对钛合金 Ti-6Al-4V 微观组织及力学性能的影响
}

\author{
李建平, 刘珍光, 李 晶 \\ (东北大学 轧制技术及连轧自动化国家重点实验室, 辽宁 沈阳 110819)
}

\begin{abstract}
摘 要: 通过异步/同步热轧实验研究了异步热轧工艺对钛合金显微组织和力学性能的影响。实验表征了试样的显微组织、力学性能、 断口形貌和微观取向。结果表明, 复杂应变路径较之简单应变路径能更好地细化晶粒, 同时提高强度和塑性, 并且表层晶粒小于中心晶 粒。异步轧制工艺相比同步轧制能更好地获得细小晶粒。异步轧制试样的强度及塑性值高于同步轧制试样相应值, 提高异步速比可提高 强度及塑性值。异步轧制试样的塑性变形机制可能是滑移, 而同步轧制试样塑性变形机制为滑移或孪晶。
\end{abstract}

关键词：异步轧制；钛合金；显微组织；力学性能

作者简介: 李建平, 男, 1958 年生, 教授, 东北大学轧制技术及连轧自动化国家重点实验室, 辽宁 沈阳 110819, 电话: 024-83688545, E-mail: ljp@mail.neu.edu.cn 